2. To: (Receiving Organization) SST RetrievaT

5. Proj./Prog./Dept./Div.:

W -320

8. Originator Renarks:

For Approval and Release

11. Receiver Remarks: 11A. Design Basel ine Document? [] Yes $X \mid$ No
3. From: (Originating organization) SST Retrieval

6. Design Authority/ Design Agent/Cog. Engr.:

JR Kriskovitch
4. Related EDT No.:

NA

7. Purchase Orcier No.:

NA

9. Equip./Component No.: P0R-007/P0R-008

10. System/Bldg./Facility: 200 General

12. Major Assm. Dwg. No.:

H-14-102610

13. Permit/Permit Application No.: NA

14. Required Response Date: Ju7y 24, 1998

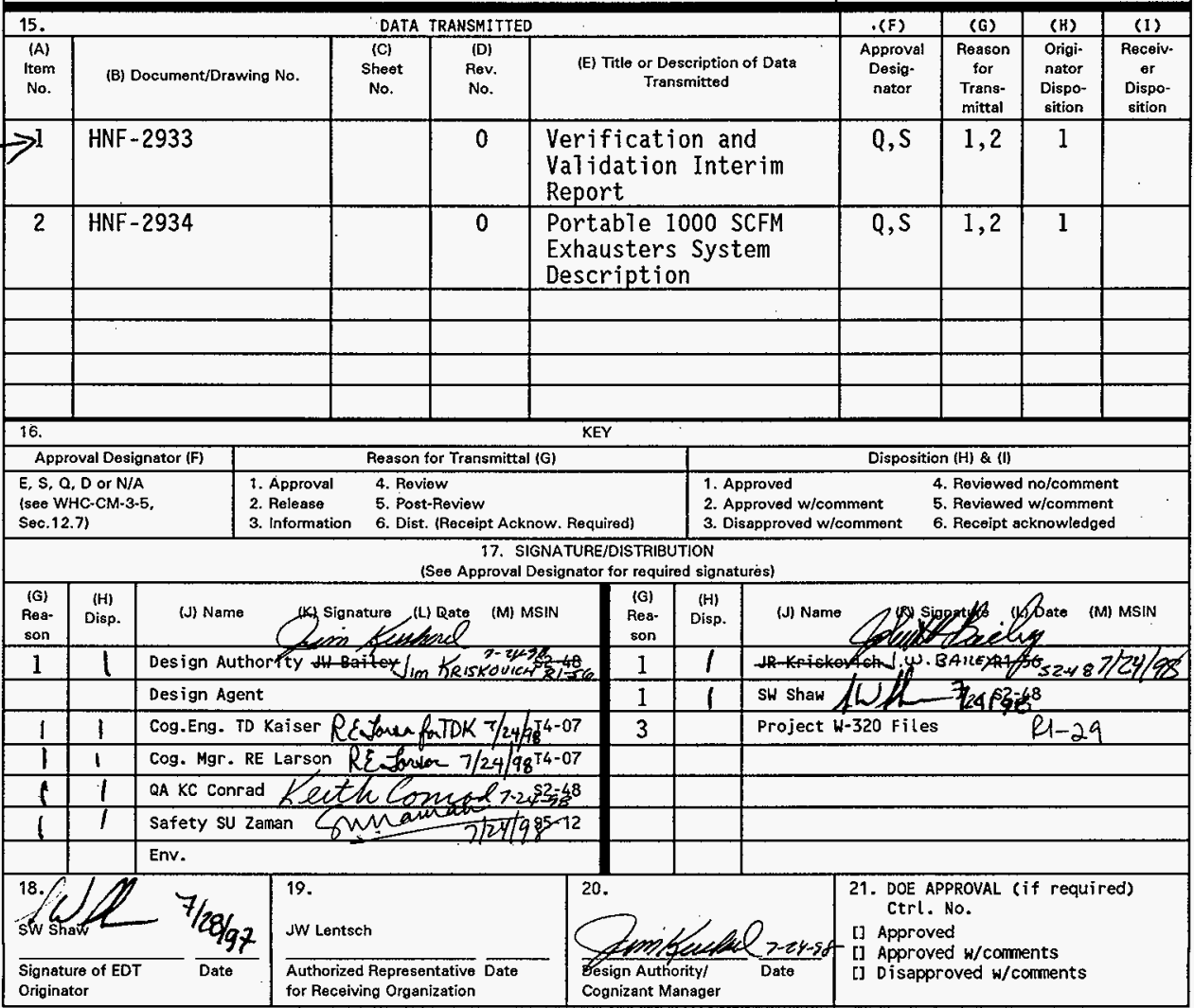


HNF-2933, Rev. 0

\section{Verification \& Validation Interim Report for Portable 1,000 CFM Exhauster Skids POR-007/Skid E and POR-008/Skid F}

\section{OD Nelson}

NHC, Richland, WA 99352

U.S. Department of Energy Contract DE-AC06-96RL13200

EDT/ECN: 622196

Org Code: 8C452

UC: 510

B\&R Code: EW3130010

Charge Code: D2M65

Total Pages: 13

Key Words: POR-007, POR-008, System Design Description, W-320, Control Mode, 1,000 CFM, Exhauster Skid, Programmable Logic Controller (PLC), Sluicing, Software, $V \& V$

Abstract: Summarizes the results of $V \& V$ tasks performed to date in the concept, requirements, design, implementation, test, installation and checkout, operation and maintenance life cycle phases.

TRADEMARK DISCLAIMER. Reference herein to any specific commercial product, process, or service by trade name, trademark, manufacturer, or otherwise, does not necessarily constitute or imply its endorsement, recomendation, or favoring by the United States Goverment or any agency thereof or its contractors or subcontractors.

Printed in the United States of America. To obtain copies of this document, contact: Document Control Services, P.O. Box 950, Mailstop H6-08, Richland HA 99352, Phone (509) 372-2420; Fax (509) 376-4989.

Xniskraden Retease Approval
$7 / 25 / 98$

Date

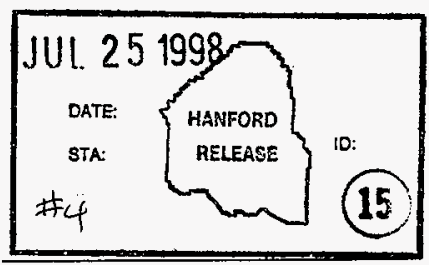

Release stamp 
Title: Portable 1,000 CFM Exhausters V\&V Interim Report
DI: HNF-2933

Page: 1 of 18

VERIFICATION AND VALIDATION (V\&V) INTERIM REPORT

FOR

PORTABLE 1,000 CAM EXHAUSTER SKIDS

POR-007-SKIDE

AND

POR-008-SKID F

Document Identifier (DI): HNF-2933

Revision 0

July 22, 1998

Prepared by:

Fluor Daniel Northwest (FDNW)

Control Systems Engineering CCAD Team 1200 Jadwin Avenue

Richland, WA

Authored by:

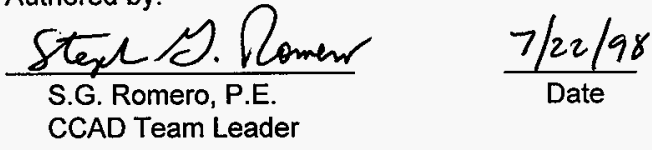

F:INSTMIEXH_SKIDIHNF_2933.V\&V

1

July 22, 1998 
Title: Portable 1,000 CFM Exhausters

DI: HNF-2933

Rev. 0

V\&V Interim Report

Page: 2 of 12

Table of Revisions

\begin{tabular}{|c|c|l|l|}
\hline Rev. & $\begin{array}{c}\text { Date of } \\
\text { Issue }\end{array}$ & \multicolumn{1}{|c|}{ Description } & \multicolumn{1}{c|}{ Remarks } \\
\hline A & $2 / 9 / 98$ & Initial review issue & $\begin{array}{l}\text { Comments expected by } \\
2 / 16 / 98\end{array}$ \\
\hline OA & $7 / 9 / 98$ & $\begin{array}{l}\text { Final review issue after previous } \\
\text { ATP exceptions cleared by latest } \\
\text { ATP (executed } 7 / 6 / 98 \text { to } 7 / 8 / 98) .\end{array}$ & $\begin{array}{l}\text { Comments expected by } \\
\text { COB } 7 / 17 / 98\end{array}$ \\
\hline 0 & $7 / 22 / 98$ & $\begin{array}{l}\text { Issued with approval for exhaust } \\
\text { skid deployment. }\end{array}$ & $\begin{array}{l}\text { Exhaust skids considered } \\
\text { ready for field deployment } \\
\text { after haveing reviewed } \\
\text { successfully completed } \\
\text { ATP: }\end{array}$ \\
\hline
\end{tabular}


Title: Portable 1,000 CFM Exhausters V\&V Interim Report

DI: HNF-2933 Rev. 0

Page: 3 of 12

\section{TABLE OF CONTENTS}

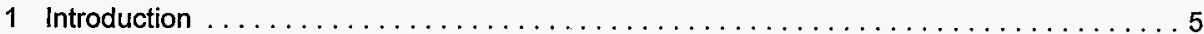

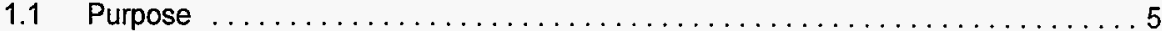

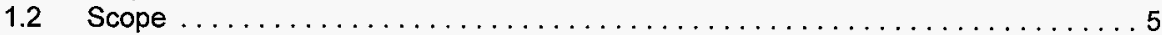

1.3 Overview .................................. 5

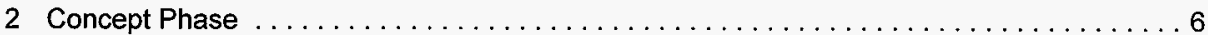

2.1 Description of V\&V Tasks Performed $\ldots \ldots \ldots \ldots \ldots \ldots \ldots \ldots \ldots \ldots$

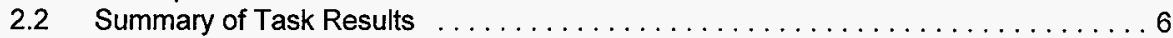

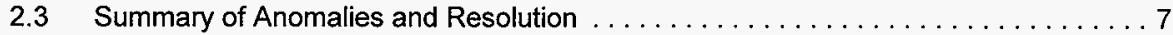

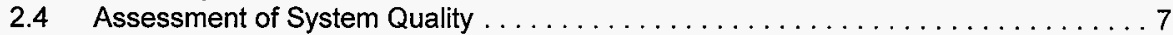

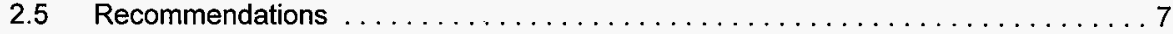

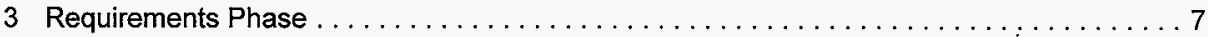

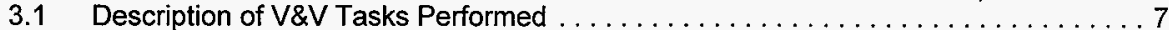

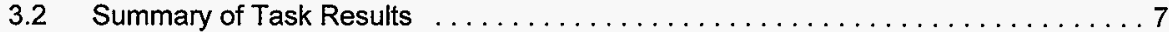

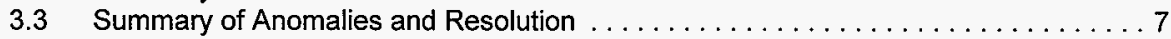

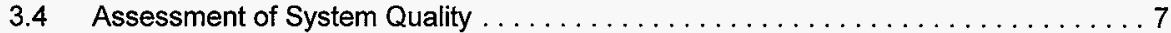

3.5 Recommendations . . . . . . . . . . . . . . . . . . . . . . . . . . 8

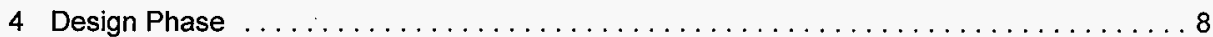

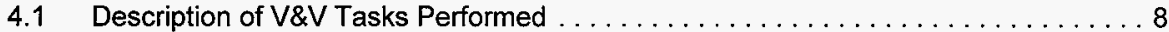

4.2 Summary of Task Results . . . . . . . . . . . . . . . . . . . 8

4.3 Summary of Anomalies and Resolution $\ldots \ldots \ldots \ldots \ldots \ldots \ldots \ldots \ldots$

4.4 Assessment of System Quality . . . . . . . . . . . . . . . . . . . 9

4.5 Recommendations .............................. 9

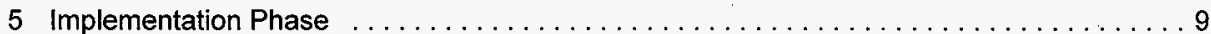

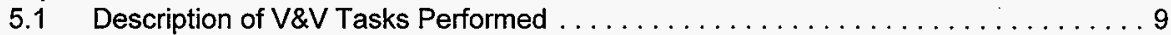

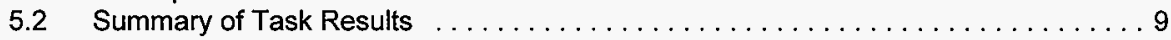

5.3 Summary of Anomalies and Resolution $\ldots \ldots \ldots \ldots \ldots \ldots \ldots \ldots \ldots \ldots \ldots$

5.4 Assessment of System Quality . . . . . . . . . . . . . . . . . . . . 9

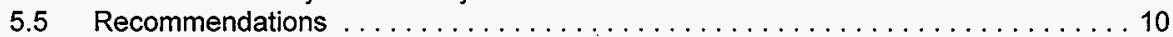

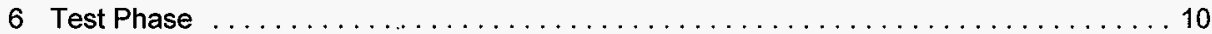

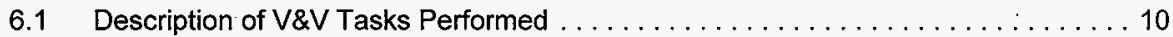

6.2 Summary of Task Results . . . . . . . . . . . . . . . . . . . . 11

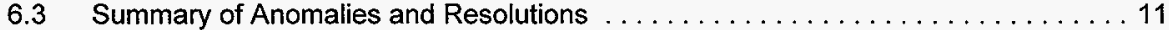

6.4 Assessment of System Quality . . . . . . . . . . . . . . . . . 11

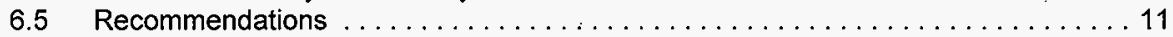

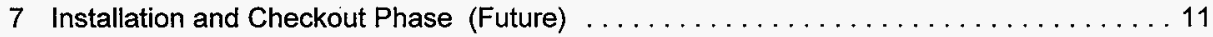

7.1 Description of V\&V Tasks Performed . . . . . . . . . . . . . . . 11

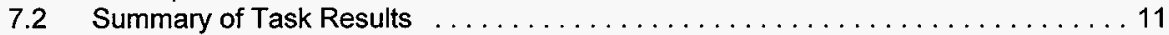


Title: Portable 1,000 CFM Exhausters

DI: HNF-2933

Rev. 0

V\&V Interim Report

Page: 4 of 12

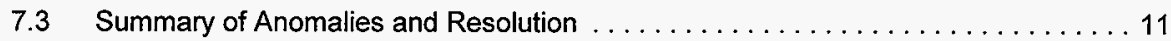

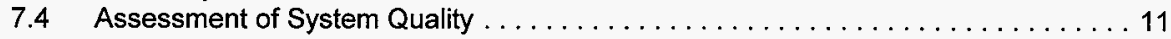

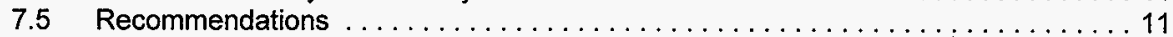

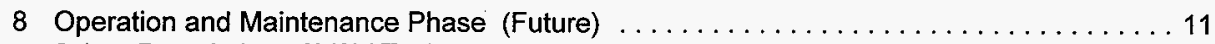

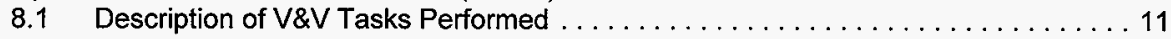

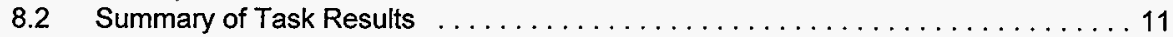

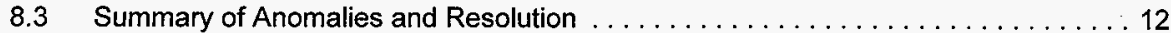

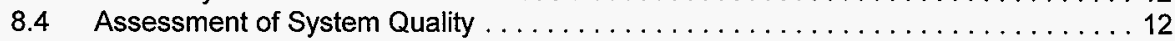

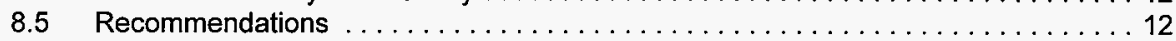


Title: Portable 1,000 CFM Exhausters

DI: HNF-2933

Rev. 0

V\&V Interim Report

Page: 5 of 12

1 Introduction

\subsection{Purpose}

This Verification and Validation (V\&V) interim report summarizes to date the results of the V\&V tasks performed in each of the following life cycle phases: concept, requirements, design, implementation, test, installation and checkout, and operation and maintenance. At the end of the installation and checkout phase, the V\&V final report will be issued. This interim report contains or references the following for each phase:

- Description of V\&V tasks performed

- Summary of task results

- Summary of anomalies and resolution

- Assessment of system quality

- Recommendations

\subsection{Scope}

This document provides a brief summary of the Software Development Life Cycle (SDLC) Phases leading up to and including the test phase. The Installation and Checkout Phase and the Operation and Maintenance Phase are not included, as yet, since the skids have yet to be installed.

The following procedures were followed where applicable to the configuration of control system software:

- HNF-PRO-431 Verification and Validation

- HNF-PRO-556 Verification and Validation Reports

Since the above procedures are intended primarily for the V\&V of non-commercial, one-of-a-kind software created from source code, in some cases they do not apply to the software configuration environment of PLC and HMl control systems. There is no source code to debug with the PLC and $\mathrm{HMI}$ control system software. This makes for less emphasis to be placed on the verification (review) and more on the validation (testing) of the software configuration. Since it will be shown through exhaustive testing that the PLC and HMI software configuration meet the intent of the functional requirements and design it makes it much less important to verify (review) the software configuration.

\subsection{Overview}

Each phase of the V\&V activities associated with the SDLC is discussed below. The phases in order are:

- Concept Phase

- Requirements Phase 
Title: Portable 1,000 CFM Exhausters

DI: HNF-2933

Rev. 0

V\&V Interim Report

Page: 6 of 12

- Design Phase

- Implementation Phase

- Test Phase

- Installation and Checkout Phase

- Operation and Maintenance Phase

\section{Concept Phase}

During this phase it is assumed (since no documentation is readily available) that the V\&V effort provided feedback to the software development process regarding the quality of the Concept phase documentation, the approach proposed by the development team and the adequacy of concept documentation for subsequent phase verification and validation tasks. It is a safe assumption since the skids perform as desired.

\subsection{Description of V\&V Tasks Performed}

The following products/documentation of the Concept Phase of the SDLC were reviewed and evaluated by the V\&V team (unless noted otherwise). Appendices $K$ and $M$ referenced in HNF-PRO431, "Verification and Validation", for this phase (section 2.3), were not available.

- Funding Authorization Documentation ${ }^{1}$ - Not available

- Project Request or Proposal - Not available

- User Statement of Need - PLC and HMI computer programming and configuration necessary to operate the exhauster skids remotely and safely during saltwell pumping or as back-ups for $W$ 320 ventilation systems on tanks C-106, or the 102-AY primary or annulus ventilation systems.

- Feasibility Study - Not available

- Cost/Benefit Analysis - Not available

- Alternatives Analysis - Not available

- Software Criticality Analysis - It was determined that the PLC and HMI software were necessary to provide the control logic and operator interface necessary to operate the exhauster skids during saltwell pumping.

- Customer Acceptance Criteria - See Functional Requirements Document (FRD)

- Software Project Management Plan - Not available

- Software Verification and Validation Plan - Not available

\section{$2: 2$ Summary of Task Results}

It was determined that the need for the exhauster skids was critical in order to enable Salt Well pumping, or as back-up to the ventilation systems associated with $W-320$. Adequate funding was then provided for the next phases.

${ }^{1}$ The underlined documentation for each SDLC phase outlined below are critical for project verification and validation. This documentation was prepared in the phase in which it is underlined and was used in subsequent phase V\&V activities. 
Title: Portable 1,000 CFM Exhausters

DI: HNF-2933

Rev. 0

V\&V Interim Report

Page: 7 of 12

\subsection{Summary of Anomalies and Resolution}

No anomalies were identified for this phase.

\subsection{Assessment of System Quality}

The concept development was considered more than adequate to lead into the next phase of requirements definition.

\subsection{Recommendations}

2.5.1 The recommendation of this phase was to proceed with the next phase of requirements definition.

\section{Requirements Phase}

Requirements were defined for the exhauster skid functions during this phase.

\subsection{Description of V\&V Tasks Performed}

The following products/documentation of the Requirements Phase of the SDLC were reviewed and evaluated by the V\&V team (except as noted). Appendices $J$ and $K$ referenced in HNF-PRO-431, "Verification and Validation", for this phase (section 2.4), were not available.

- User Statement of Need - See above.

- Software Criticality Analysis - See above.

- Software Requirements Specifications - See FRD.

- Software Requirements Interface Analysis - See FRD.

- System Test Plan - Validation by ATP.

- Acceptance Test Plan - See previous ATP's performed on skids 007 and 008.

- User Documentation - See FRD.

\subsection{Summary of Task Results}

The functional requirements for the exhauster skid software were determined and it was decided that the best solution was to implement a PLC/HMI control system. The Allen-Bradley (A-B) SLC 500 was selected as the PLC along with the A-B PLC programming software. Wonderware's InTouch was selected as the HMI software.

\subsection{Summary of Anomalies and Resolution}

No anomalies were identified for this phase.

\subsection{Assessment of System Quality}


Title: Portable 1,000 CFM Exhausters

DI: HNF-2933

Rev. 0

V\&V Interim Report

Page: 8 of 12

Since PLC's and HMI software were being used with great success and since PLC's are considered very reliable, the proposed $\mathrm{PLC} / \mathrm{HMI}$ control system quality was assessed to be very high.

\subsection{Recommendations}

3.5.1 Use the PLC/HMI control system architecture including the appropriate software.

\subsubsection{Proceed with the design phase.}

\section{Design Phase}

The tagname database for the $\mathrm{HMI}$ and the PLC I/O designations were determined and documented during this phase. Detailed design of the exhauster skids was performed during this phase and all of the major engineering and design disciplines were involved: civil/structural, control systems, electrical, HVAC and mechanical. The PLC programming and HMI configuration were performed during this phase.

\subsection{Description of V\&V Tasks Performed}

The following products/documentation of the Design Phase of the SDLC were reviewed and evaluated by the V\&V team (except as noted). Appendix $J$ referenced in HNF-PRO-431, "Verification and Validation", for this phase (section 2.5), was not available.

- Software Requirements Specifications - Function fulfilled by the FRD and the P\&ID's.

- Software Design Description - Function fulfilled by the FRD and the P\&ID's.

- Interface Requirements Documentation - Function fulfilled by the FRD and P\&ID's.

- Interface Design Documentation - Function fulfilled by the P\&ID's and wiring diagrams.

- Component Test Plan - Certain Safety Class items subjected to the vendor's certification process.

- Integration Test Plan - Function performed by the ATP's.

- Test Design - As shown in the ATP's.

- User Documentation - Detailed design drawings, setpoint spreadsheets and PLC program printouts.

- Standards

Governing Regulations

Policies

Procedures

Departmental Standards

\subsection{Summary of Task Results}

All software design was done in accordance with existing standards and interface requirements. 


\subsection{Summary of Anomalies and Resolution}

No anomalies were identified for this phase.

\subsection{Assessment of System Quality}

The software configuration was given a discipline check in which it was determined that the system quality would be high if the design were implemented correctly.

\subsection{Recommendations}

\subsubsection{Proceed to the Implementation Phase.}

5 Implementation Phase

The following products/documentation of the Implementation Phase of the SDLC were reviewed and evaluated by the V\&V team (except as noted). Appendix $\mathrm{J}$ referenced in HNF-PRO-431, "Verification and Validation", for this phase (section 2.6), was not available.

\subsection{Description of V\&V Tasks Performed}

- Source Code Traceability Analysis - Not applicable to PLC/HMI based control system software.

- Source Code Evaluation - Not applicable to PLC/HMI based control system software.

- Source Code Documentation - PLC program documented internally with the PLC programming software documentation function.

- Test Case Generation - PLC/HMI based control system software tested extensively during implementation. PLC programmed to allow simulation of inputs and outputs.

- Test Procedure Generation - ATP preparation completed during this phase.

- Component Test Execution - PLC/HMI based control system software tested extensively during implementation. PLC programmed to allow simulation of inputs and outputs.

\subsection{Summary of Task Results}

The PLC and HMI software were configured to meet the design and the functional requirements. Testing was continued throughout the iterative cycle of software implementation. The testing showed the software configuration met the desired goals.

\subsection{Summary of Anomalies and Resolution}

No anomalies were identified for this phase.

\subsection{Assessment of System Quality}

The iterative cycle of testing during the implementation showed the software configuration to be of high quality. 
Title: Portable 1,000 CFM Exhausters V\&V Interim Report

DI: HNF-2933

Page: 10 of 12

\subsection{Recommendations}

\subsubsection{Proceed to the Test Phase.}

\section{Test Phase}

In the sections below, the Acceptance Test Procedures for the Portable 1,000 CFM Exhausters, POR-007-SKID E and POR-008-SKID F, are examined and the test results are summarized with recommendations below. The ATP for the POR-007-SKID E portable exhauster skid is numbered HNF-2686. The ATP for the POR-008-SKID F portable exhauster skid is numbered HNF-2687.

The following tests were performed as part of the main ATP (except as noted). Appendix $\mathrm{K}$ referenced in HNF-PRO-431, "Verification and Validation", for this phase (section 2.7), is not yet available.

ATP Section and Description:

5.1 POWER SYSTEM CHECK

5.2 PRESSURE DECAY TEST

5.3 GLYCOL SYSTEM LEAK TEST

5.4 EXHAUSTER FAN CHECK

5.5 HEAT TRACE CHECK

5.6 FILTER \#1 DP INTERLOCKJALARM CHECK

5.7 FILTER \#2 DP INTERLOCKIALARM CHECK

5.8 FILTER \#1 \& \#2 DP INTERLOCKIALARM CHECK

5.9 STACK FLOW INTERLOCKIALARM CHECK

5.10 SEAL POT INTERLOCKIALARM CHECK

5.11 GLYCOL INTERLOCKIALARM CHECK

5.12 THERMOCOUPLE INTERLOCKIALARM CHECK

5.13 PLENUM PRESSURE DP INTERLOCKIALARM CHECK

5.14 GLYCOL HEATER TEST

5.15 FAN INLET VACUUM INTERLOCKIALARM CHECK-PRESSURE CONTROL

5.16 STACK FLOW INTERLOCKIALARM CHECK-PRESSURE CONTROL

5.17 HIGH INLET VACUUM INTERLOCK CHECK-HIGH VACUUM

5.18 STACK FLOW ALARM CHECK-HIGH VACUUM

5.19 FUNCTIONAL TEST - FLOW CONTROL (1000 CFM)

5.20 FUNCTIONAL TEST - FLOW CONTROL (500 CFM)

5.21 FUNCTIONAL TEST - PRESSURE CONTROL

5.22 FUNCTIONAL TEST - HIGH VACUUM

5.23 RESTORATION

\subsection{Description of V\&V Tasks Performed}

The main task performed by the ATP's was to validate the operation of the exhauster skids as represented by the list of tests in section 1.3 above. 
Title: Portable 1,000 CFM Exhausters V\&V Interim Report

DI: HNF-2933

Rev. 0

Page: 11 of 12

\subsection{Summary of Task Results}

In general the test results indicate that the exhauster skids operate as intended with all safety and shutdown functions in working order.

\subsection{Summary of Anomalies and Resolutions}

The only anomaly identified during the skid ATP's was the overly complex nature of the PLC program. While the PLC program as it exists at present performs all of the required functions as identified in the ATP, it is very hard to follow and will eventually lead to future mistakes in program modifications which may or may not result in safety problems.

\subsection{Assessment of System Quality}

Due to the validation by testing the overall system quality is considered to be more than sufficient to perform the desired functionality.

\subsection{Recommendations}

6.5.1 The 1,000 SCFM exhauster skids $E$ and $F$ are ready to installed, if necessary due to failure of primary tank or annulus ventilation systems on AY-102 or C-106, to provide the backup tank or annulus air exhaust functions.

6.5.2 While the PLC program as it exists at present performs all of the required functions as identified in the ATP, it should be rewritten so that it will be more programmer-friendly when implementing new or changed functionality in the future.

7 Installation and Checkout Phase (Future)

7.1 Description of V\&V Tasks Performed

7.2 Summary of Task Results

7.3 Summary of Anomalies and Resolution

7.4 Assessment of System Quality

\subsection{Recommendations}

8 Operation and Maintenance Phase (Future)

8.1 Description of V\&V Tasks Performed

8.2 Summary of Task Results 
Title: Portable 1,000 CFM Exhausters V\&V Interim Report'

8.3 Summary of Anomalies and Resolution

8.4 Assessment of System Quality

8.5 Recommendations 